
коррекции у детей и подростков

\title{
Contacts:
}

Talashova Svetlana Vadimovna, MD, assistant professor of Department of Pharmacology and Pharmaceutic Technologies of Yaroslavl State Medical Academy

Address: Revolyutsionnaya Street, 5, Yaroslavl, RF, 150000, Tel.: (4852) 30-31-40, e-mail: stalash@rambler.ru Article received: 15.07.2013, Accepted for publication: 26.08.2013

В 2011 г. был принят Федеральный закон № 323 “Об основах охраны здоровья граждан в Российской Федерации”, а в 2012 г. - приказ № 1175н "Об утверждении порядка назначения и выписывания лекарственных препаратов". Изменения в правовом поле деятельности врачей-педиатров в лечебно-профилактических учреждениях и провизоров (фармацевтов) на аптечных предприятиях, особенно на начальном этапе реализации указанных законопроектов, обусловливают необходимость комплексного консультирования пациента, поскольку вместо привычного рецепта с фирменным названием препарата он получит рецепт с международным непатентованным наименованием, который может вызвать вопросы. Современные витаминно-минеральные комплексы как фармакотерапевтическая группа и товарная категория имеют специфические особенности. В статье приводится пример комплексного консультирования по витаминно-минеральной коррекции рациона питания детей и подростков, объясняется необходимость их приема, особенности применения и критерии качества предлагаемой аптеками продукции.

Ключевые слова: законодательная база, витаминно-минеральные комплексы, педиатрия, комплексное консультирование.

(Вопросы современной педиатрии. 2013; 12 (4): 126-129)

Лечебно-профилактические учреждения (ЛПу) и аптечные предприятия - это два последовательных звена современной системы оказания лекарственной помощи взрослому и детскому населению Российской Федерации (РФ). Врач-педиатр консультирует родителей по вопросам улучшения качества жизни ребенка, назначает соответствующую терапию, объясняет особенности приема того или иного лекарственного средства. Провизор (фармацевт) осуществляет консультирование и продажу рецептурных препаратов при наличии обоснования (рецепта с назначением врача), а также препаратов безрецептурного отпуска.

Целесообразность работы Лпу и аптеки в тандеме очевидна, т. к. врач на поликлиническом приеме не имеет возможности предугадать, какие вопросы возникнут у пациента в аптеке при покупке рекомендованного лекарственного средства, и какие дополнительные разъяснения ему будут необходимы. Преемственность

S.V. Talashova, A.G. Khrykova, A.A. Trubnikov

Yaroslavl State Medical Academy, Russian Federation

\section{Experience of Complex Consulting on the Problem of Vitamin and Mineral Correction in Children and Adolescents by Pediatrician at the Medical Institution and Pharmacist at Drugstore}

Since the Federal Law № 323 "On the Basics of Russian Federation Population Health Protection" (2011) and the Order № 1175n "On Confirming the Procedure of Appointing and Prescribing Medicines" (2012) were administered, the legislative field of pediatricians' and pharmacists' activity has been changed. The present situation, especially at the initial stage of the mentioned laws realization, requires the necessity of patients' complex consulting as instead of the prescription with a definite medicine's name they will receive the one with the international nonproprietary name which might cause many questions. Modern complexes of vitamins and minerals have their own specific features as a medicinal group and a commodity. Based on the mentioned aspects, the article provides a practical example of complex consulting on the problem of vitamin and mineral correction in children and adolescents' nutrition and explains the necessity of vitamin and mineral complexes application, as well as details their administration peculiarities and the criteria of the quality of the products provided by the chemists.

Key words: legislative base, vitamin and mineral complexes, pediatrics, complex consulting.

(Voprosy sovremennoi pediatrii — Current Pediatrics. 2013; 12 (4): 126-129) 
в работе врача и провизора повышает комплаентность терапии, а, следовательно, и ее эффективность.

Особое место среди всего разнообразия лекарственных средств, применяемых на территории РФ, занимают витаминно-минеральные комплексы (ВМК). При кажущейся простоте назначения и консультирования по их применению у детей и подростков эта фармакотерапевтическая группа имеет особенности, которые необходимо учитывать. - Приказом Министерства здравоохранения РФ от 20 декабря 2012 г. № 1175н “Об утверждении порядка назначения и выписывания лекарственных препаратов, а также рецептурных бланков на лекарственные препараты, порядка оформления указанных бланков, их учета и хранения" предусмотрено назначение и выписывание лекарственных препаратов по международному непатентованному наименованию (МHН), при его отсутствии - по группировочному наименованию, а в случае отсутствия у препарата МНН или группировочного наименования - по торговому наименованию [1].

Этот приказ является подзаконным актом к вступившему в силу Федеральному закону от 21 ноября 2011 г. № 323-Ф3 “Об основах охраны здоровья граждан в Российской Федерации". В ст. 74 данного закона говорится о том, что провизор (фармацевт) не в праве предоставлять при назначении курса лечения пациенту недостоверную, неполную или искаженную информацию об используемых лекарственных препаратах, о медицинских изделиях, в т. ч. скрывать сведения о наличии в обращении аналогичных лекарственных препаратов [2].

Указанные правовые документы являются регламентирующими для педиатра и провизора. Хотя ВМК и относятся к безрецептурным препаратам и могут быть просто назначены (рекомендованы) к приему, важно понимать, что они не могут быть выписаны по МНH, Т.К. представляют собой комбинацию премиксов (исходных субстанций витаминов и минералов). Соответственно, в аптеке провизору нет необходимости предлагать покупателю несколько вариантов ВМК по различным ценам.

- Характерной особенностью ВМК является то, что их нельзя дифференцировать, как это принято в современной фармакологии, на оригинальные препараты (впервые синтезированные молекулы) и дженерические (воспроизведенные молекулы) по той же самой причине - ввиду отсутствия МНН. Специалистам важно понимать это для того, чтобы иметь иные критерии оценки качества ВМК. Для последних ключевым показателем эффективности и безопасности является качество премиксов. Целесообразно оценивать их странупроизводитель; состав (на отсутствие технологической, фармакологической и физико-химической несовместимости); используемые концентрации премиксов и их соответствие установленным нормам, а также технологию получения готовой лекарственной формы.

- В настоящее время ВМК регистрируют и в качестве лекарственных средств, и в качестве биологически активных добавок (БАД). Специалистам необходимо иметь четкое представление о механизме процесса регистрации. Его двойственность связана с тем, что фирма-производитель вправе зарегистрировать препарат либо в качестве лекарственного средства, при условии доказанной клинической эффективности заявляемой фармакологической активности, либо в качестве БАД к пище - при условии, что препарат подпадает под определение (композиция натуральных или идентичных натуральным веществ, предназначенных для непосредственного приема с пищей или введения в состав пищевых продуктов с целью обогащения рациона отдельными пищевыми или биологически активными веществами и их комплексами) [3]. Следовательно, современные ВМК имеют основания быть зарегистрированными и как лекарственное средство, и как БАД. Отсюда следует основной вывод: существующая двойственность - исключительно вопрос регистрации. Это ставит БАД и лекарственные средства в абсолютно равное положение при условии, что производитель занимается выпуском и лекарственных средств, и БАД. Необходимо отметить, что регистрация БАД протекает в более короткие сроки, по сокращенной схеме по сравнению с регистрацией лекарственных средств и, соответственно, обходится производителю дешевле.

Наряду с особенностями назначения и консультирования в отношении ВМК, с которыми сталкиваются специалисты, конечный потребитель испытывает не меньшие сложности. Некоторые из них требуют разъяснения на приеме у врача-педиатра, а некоторые должны быть озвучены и провизором в аптеке.

Врач-педиатр на консультативном приеме сталкивается с существованием множества мифов и предубеждений в сознании родителей по вопросам витаминноминеральной коррекции у детей и подростков. При назначении этой фармакотерапевтической группы родителей необходимо информировать как минимум по 4 основным направлениям.

- Независимо от того, где и как питается ребенок (дома, в детском саду, в школе или санатории), он не получает с пищей достаточного количества витаминов и микроэлементов $[4,5]$. Поэтому важно, чтобы ребенок получал их из дополнительного источника, т.е. из витаминно-минеральных комплексов.

- Принимать витаминные комплексы необходимо регулярно, поскольку их нехватка ощущается постоянно. Из пищи в лучшем случае можно получить половину требуемого количества. Перерыв в приеме ВМК целесообразно сделать летом, когда ситуация с поступлением витаминов улучшается в связи с большим количеством овощей и фруктов. Минимальный курс приема составляет 2-4 нед, при этом необходимым условием является адекватное поступление жидкости (соблюдение питьевого режима) [6].

- По фармакологической эффективности ВМК, продаваемые в аптеке, не только не уступают натуральным витаминам, а превосходят их, т.к. усвояемость витаминов из продуктов питания теоретически составляет 90-95\%, а реально может составлять 50-60\% или даже вообще отсутствовать [7].

- Витамины и минералы необходимы для гармоничного роста и развития организма. Однако следует понимать, 
что при имеющихся серьезных заболеваниях у ребенка ему необходимо в первую очередь проводить специализированное лечение, а прием ВМК можно рассматривать только как поддерживающее мероприятие.

Фармацевту необходимо реализовывать свою просветительскую функцию, информировать родителей и отвечать на возникающие вопросы при продаже лекарственных средств. Если мы говорим о ВМК для детей и подростков, то должны быть учтены следующие моменты.

- Не следует бояться принимать препараты, содержащие комбинации витаминов и минералов. В той пище, которую человек съедает за завтраком или обедом, присутствуют всевозможные комбинации, и мы не боимся, что они нейтрализуют друг друга в организме. Так же обстоит дело и с современными ВМК. Используя специальные технологические приемы, производители добиваются того, чтобы витамины и минералы, усиливающие действие друг друга, усваивались одновременно, а те, которые конкурируют при всасывании, имели различное время высвобождения из таблетки или капсулы [8].

- При назначении витаминов на фоне применения других лекарственных средств необходимо учитывать возможности и особенности их взаимодействия. Целесообразно начинать прием ВМК сразу после основного курса лекарственных средств, и в частности антибиотиков [9].

- Витамины необходимо принимать в основной прием пищи, а не натощак, т.к. при этом отмечается максимальная биодоступность и отсутствие диспепсических явлений.

- При приеме ВМК следует придерживаться инструкции, соблюдать суточные дозировки, предусмотренные возрастными нормами потребления. С одной стороны, не следует допускать непреднамеренной передозировки, а с другой - не применять ВМК слишком короткими курсами, что не даст возможности детскому организму получить адекватное количество препарата. Также нельзя принимать ВМК по истечении срока годности.

Таким образом, выше сформулировано 3 особенности ВМК, которые необходимо знать специалистам (педиатру и провизору), 4 основные рекомендации пациентам от педиатра и 4 рекомендации покупателям в аптеке от лица провизора.

Опыт нашей работы в Детской поликлинике на консультативном приеме наглядно продемонстрировал целесообразность проведения такой комплексной работы. На наблюдаемом участке увеличился процент детей, регулярно получающих ВМК, в то время как, по статистическим данным, обеспеченность детского населения витаминами и минералами в РФ считается неудовлетворительной [10]. Повысилась информированность родителей в вопросах рационального питания ребенка, что усилило приверженность к терапии и, соответственно, привело к повышению эффективности терапии.

Комплексное консультирование проводилось в т.ч. и на примере линейки витаминно-минеральных средств "Пиковит", поскольку данная продукция представлена во всех возрастных категориях и дозировках, утверж- денных Министерством здравоохранения РФ, а также рекомендована Союзом педиатров России.

Витаминные препараты компании "KRKA" выпускаются на заводе по производству твердых фармацевтических форм «Нотол", расположенном в Словении. Это производство отличает уникальная технология вертикальной подачи материалов; оно управляется компьютерами при помощи эффективной многоуровневой системы.

Выпускаемые компанией ВМК соответствуют всем международным стандартам качества, разработанным для фармацевтической продукции: Международным стандартам GMP (Good Manufactured Practice); ISO серии 9000 и OHSAS 18001:1999.

Компания “КРКА” регистрирует свою продукцию и как лекарственные препараты, и как БАД к пище, при этом действующие вещества (премиксы) идентичны по качеству, обе позиции выпускаются на одном и том же фармацевтическом производстве, при соблюдении одних и тех же стандартов качества. Все позиции линейки относятся к безрецептурному отпуску.

Актуальность специальных комплексов продиктована необходимостью, наряду с комплексом витаминов и минералов, предложить ребенку и другие эссенциальные вещества. Например, пребиотик оправдан в составе ВМК при нарушении механизмов всасывания и признаках дисбиоза кишечника у ребенка [11]; $\omega_{3}$ (эйкозапентаеновая и декозагексаеновая кислота) нужны для сбалансированного развития и работы нервной системы, мозга, зрения, а также адекватной умственной деятельности растущего организма и развития когнитивных способностей. Очень важно, чтобы помимо $\omega_{3}$ ВМК также содержал и комплекс витаминов, из которых особенно существенны витамины А, Д, Е, поскольку

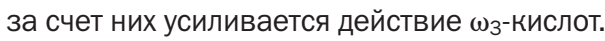

Внимание специалистов к $\omega_{3}$ продиктовано тотальным дефицитом данных веществ в рационе питания детей и подростков [12].

Для удобства работы врача и широты выбора пациента, компания КРКА специально разработала линейку витаминно-минеральных средств "Пиковит", которые применяют с 1 года до 14 лет. Кроме того в последнее время линейка расширена специализированными позициями - "Пиковит Пребиотик" (содержит 10 важных витаминов и пребиотик - олигофруктозу) и "Пиковит Омега 3" (в его составе присутствуют 10 витаминов и (зз-жирные кислоты) с возраста 3 лет.

Таким образом, тандем педиатра и провизора весьма важен для конечного потребителя, т. к. позволяет лучше ориентироваться в вопросах минерально-витаминной коррекции рациона питания детей и подростков, укрепляет взаимодействие специалистов в области педиатрии и фармации, помогает лучше ориентироваться в сложных вопросах современной фармакологии, в частности обладать потенциалом знаний для грамотного назначения и обоснованной рекомендации современных ВМК, а также позволяет лучше узнать специфику работы друг друга, что укрепляет взаимное доверие и уважение. В итоге мы способствуем оздоровлению детского населения, большему доверию со стороны родителей, а, следовательно, и большей степени комфорта в работе - на поликлиническом приеме и в торговом зале аптеки. 


\section{REFERENCES}

1. Prikaz Minzdrava Rossii ot 20 dekabrya 2012 g. № $1175 n$ "Ob utverzhdenii poryadka naznacheniya i vypisyvaniya lekarstvennykh preparatov, a takzhe retsepturnykh blankov na lekarstvennye preparaty, poryadka oformleniya ukazannykh blankov, ikh ucheta khraneniya" [Directive of the Ministry of Health of Russian Federation № 1175n “Adoption of the procedure of prescription and dismissal of medicines, prescription forms, as well as procedural formalities, register and storage of the mentioned forms"].

2. Federal'nyi zakon ot 21 noyabrya 2011 g. № 323-FZ "Ob osnovakh okhrany zdorov'ya grazhdan v Rossiiskoi Federatsii" [Federal Law № 323-FZ “On fundamental healthcare principles in the Russian Federation” dated November 21, 2011].

3. Pilat T. L., Ivanov A.A. P32 Biologicheski aktivnye dobavki k pishche (teoriya, proizvodstvo, primenenie) [P-32 Nutritional Supplement. Theory, Producing, Application]. Moscow, Avvallon, 2002. 710 p.

4. "Normy fiziologicheskikh potrebnostei dlya detei raznogo vozrasta v osnovnykh pishchevykh veshchestvakh i energii" [Standard deficiency needs of children of different age in essential nutrients and energy]. Moscow, Minzdrav RF, 1991.

5. Metod. rekomendats. MR 2.3.1.2432-08: Ratsional'noe pitanie. Normy fiziologicheskikh potrebnostei $v$ energii $i$ pishchevykh veshchestvakh dlya razlichnykh grupp naseleniya Rossiiskoi Federatsii. Federal'naya sluzhba po nadzoru v sfere zashchity prav potrebitelei i blagopoluchiya cheloveka. Vvedeny s 18 dekabrya 2008 g [Guidance Manual GM 2.3.1.2432-08: Standard deficiency needs in essential nutrients and energy of different groups of population of the Russian Federation. Federal Supervision Service for Consumer Rights Protection and People Welfare. Effective as of December 18, 2008].

6. Gromova O.A. Farmatsevticheskii vestnik - Pharmacological Bulletin. 2003; 2: 16-18.

7. Spirichev V.B. Skol'ko vitaminov cheloveku nado? [What is Human Need for Vitamins?] Moscow, 2000. 236 p.

8. Shikh E. V. RMZh — Russian Medical Journal. 2006; 4: 1225-1231.

9. Kukes V.G., Tutel'yan V.A. Vitaminy i mikroelementy $v$ klinicheskoi farmakologii [Vitamins and Microelements in Clinical Pharmacology]. Moscow, Paleya-M, 2001. 489 p.

10. Korovina N.A. RMZh - Russian Medical Journal. 2003; 11 (22): 1235-1237.

11. Ershova I. B., Vysotskii A.A., Tkachenko V.I. Zdorov'e rebenka Child Health. 2008; 2 (11): 37-42.

12. Kon' I.Ya., Shilina N. M., Vol'fson S. V., Georgievna O. V. Lechashhij vrach — Practicing Doctor. 2013; 06 (1): 25-32. 